\title{
BMJ
}

\section{Mortality in men admitted to hospital with acute urinary retention: database analysis}

\author{
James N Armitage, urology research fellow, ${ }^{1}$ Nokuthaba Sibanda, research fellow, ${ }^{2}$ Paul I Cathcart, urology \\ registrar, ${ }^{1}$ Mark Emberton, reader in interventional oncology, ${ }^{3}$ Jan H P van der Meulen, reader in public health \\ medicine and clinical epidemiology ${ }^{2}$
}

Clinical Effectiveness Unit, Royal College of Surgeons of England, London WC2A 3PE

${ }^{2}$ Health Services Research Unit, London School of Hygiene and Tropical Medicine, London

${ }^{3}$ Division of Surgery and Interventional Science, University College Hospital,

London

Correspondence to: J H P van der Meulen jan.vandermeulen@lshtm.ac.uk

doi:10.1136/bmj.39377.617269.55

\section{ABSTRACT}

Objectives To investigate mortality in men admitted to hospital with acute urinary retention and to report on the effects of comorbidity on mortality.

Design Analysis of the hospital episode statistics database linked to the mortality database of the Office for National Statistics.

Setting NHS hospital trusts in England, 1998-2005.

Participants All men aged over 45 who were admitted to NHS hospitals in England with a first episode of acute urinary retention.

Main outcome measures Mortality in the first year after acute urinary retention and standardised mortality ratio against the general population.

Results During the study period, 176046 men aged over 45 were admitted to hospital with a first episode of acute urinary retention. In 100067 men with spontaneous acute urinary retention, the one year mortality was $4.1 \%$ in men aged $45-54$ and $32.8 \%$ in those aged 85 and over. In 75979 men with precipitated acute urinary retention, mortality was $9.5 \%$ and $45.4 \%$, respectively. In men with spontaneous acute urinary retention aged $75-84$, the most prevalent age group, the one year mortality was $12.5 \%$ in men without comorbidity and $28.8 \%$ in men with comorbidity. The corresponding figures for men with precipitated acute urinary retention were $18.1 \%$ and $40.5 \%$. Compared with the general population, the highest relative increase in mortality was in men aged 45-54 (standardised mortality ratio 10.0 for spontaneous and 23.6 for precipitated acute urinary retention) and the lowest for men 85 and over (1.7 and 2.4, respectively). Conclusions Mortality in men admitted to hospital with acute urinary retention is high and increases strongly with age and comorbidity. Patients might benefit from multi-disciplinary care to identify and treat comorbid conditions.

\section{INTRODUCTION}

Acute urinary retention is a severe complication of benign prostatic hyperplasia. With an ageing population, it represents a major public health issue in the western world. The reported incidence of acute urinary retention in large population based studies varies from 2.2 to 6.8 per 1000 men per year. ${ }^{1-4}$ As many as one in
10 men in their 70s may experience acute urinary retention within five years. ${ }^{1}$ It is a urological emergency that requires immediate treatment with a urinary catheter. After the acute period, most men will be offered a trial without catheter and about $60 \%$ will resume spontaneous voiding. ${ }^{5}$ In the United Kingdom, about one in five will undergo further surgical treatment in the next six months, but about $15 \%$ will experience a recurrence within the same time period. ${ }^{3}$

Although acute urinary retention is a direct manifestation of progression of benign prostatic hyperplasia, several studies have also found associations with major morbidities. ${ }^{36-8}$ Occurring either spontaneously or after a precipitating event, it may therefore be a "harbinger" of severe systemic disease. We studied to what extent the occurrence of acute urinary retention among men admitted to hospital confers an increased risk of death compared with men in the general population of similar age.

\section{METHODS}

Data

We extracted data from the hospital episode statistics (HES) database, an administrative database of all admissions to NHS hospitals in England. A unique patient identifier allowed us to link records of different hospital admissions in the same patient. Each record contains diagnostic fields coded according to ICD-10 (international classification of diseases, 10th revision) and operative procedure fields coded according to the UK Tabular List of the Classification of Surgical Operations and Procedures. ${ }^{9}$ For all admissions after 1 April 1998, the HES database was linked to the mortality database of the Office for National Statistics. ${ }^{1011}$ In $2.4 \%$ of men who were reported as having died after acute urinary retention, we found a record of a subsequent hospital admission. For these contradictory results, we considered the information on death to be incorrect and therefore analysed these men as being alive until the end of the study period.

\section{Definitions}

A patient was considered to have had primary acute urinary retention (acute urinary retention for the first 
time) if there was no record in the HES database of a previous admission for this condition in at least the preceding six months. We chose a period of six months because about $80 \%$ of men who experience recurrence do so within this time period. ${ }^{4}$

We defined acute urinary retention (R33) as spontaneous if it was recorded in the first diagnostic field or if benign prostatic hyperplasia (N40) was the primary diagnosis and acute urinary retention was recorded in another diagnostic field. In all other cases we considered it to be precipitated. ${ }^{412}$

\section{Inclusion criteria}

To identify admissions of men aged over 45 who had primary acute urinary retention, we followed a stepwise process. Firstly, we selected the records of all 229089 men who were admitted at least once with an ICD-10 code indicating acute urinary retention (R33) in any of the first seven diagnostic fields from 1 April 1998 to 31 March 2005. Secondly, we sequentially deleted the records of 29924 patients with codes for prostate cancer (ICD-10 code C61), 1150 patients with codes for multiple sclerosis (G35), and 6380 patients with codes for Parkinson's disease (G20) in any diagnostic field of any record. Thirdly, we excluded the records of 15592 men who were admitted for acute urinary retention in the period from 1 April 1998 to 30 September 1998 to include only men with primary acute urinary retention.

\section{Identification of comorbidity}

We used an adaptation of the Charlson score designed for use with administrative data. ${ }^{1314}$ This score was validated in HES data for patients undergoing urological cancer surgery in England. ${ }^{15}$ Comorbid disease was defined as present if it appeared in the records of the index admission (the admission for primary acute urinary retention) or of admissions that occurred in the six months before the index admission.

\section{Statistical analysis}

We used the Kaplan-Meier method to estimate age specific mortality within 90 days and one year after primary acute urinary retention. To compare mortality within the first year with that of men in the general population, we calculated standardised mortality ratios according to age and comorbidity. Standard rates were mortalities specific for age group and calendar year for men in the general population of England for 1999-2005. The standardised rates were calculated by dividing the mid-year estimate of the number of men within an age group alive in England and Wales by the number that died during that year. The confidence intervals for the standardised mortality ratios were obtained using Byar's approximation. ${ }^{16}$

\section{RESULTS}

From 1 October 1998 to 31 March 2005, 176046 men were admitted to NHS hospitals with a diagnosis of primary acute urinary retention (table 1). Of these men, 100067 (56.8\%) had spontaneous acute urinary retention (mean age 73.5 (SD 10.5) years) and 75979 $(43.2 \%)$ had precipitated retention (mean age 74.5 SD 10.9 ) years). In all age groups, mortality was higher in men with precipitated acute urinary retention.

Overall, $14.7 \%$ of men with spontaneous acute urinary retention and $25.3 \%$ men with precipitated acute urinary retention died within the first year (table 1). About half of these deaths (54.9\%) occurred within the first 90 days.

In men with spontaneous acute urinary retention, mortality at one year increased strongly with age, from $4.1 \%$ in patients aged $45-54$ to $32.8 \%$ in those aged 85 and over (table 1). In men with precipitated acute urinary retention, mortality at one year increased

Table 1 Age specific mortality within 90 days and one year after spontaneous and precipitated primary acute urinary retention and standardised mortality ratios (SMR) against the general population of England

\begin{tabular}{|c|c|c|c|c|c|c|}
\hline \multirow[b]{3}{*}{ Age group } & \multirow{3}{*}{$\begin{array}{c}\text { Total } \\
\text { admissions }\end{array}$} & \multicolumn{4}{|c|}{ Mortality } & \multirow{3}{*}{$\begin{array}{c}\text { SMR } \\
(95 \% \mathrm{Cl})\end{array}$} \\
\hline & & \multicolumn{2}{|c|}{90 days } & \multicolumn{2}{|r|}{1 year } & \\
\hline & & Deaths & Rate $(95 \% \mathrm{Cl})$ & Deaths & Rate $(95 \% \mathrm{Cl})$ & \\
\hline \multicolumn{7}{|c|}{ Spontaneous acute urinary retention } \\
\hline $45-54$ & 5580 & 119 & 2.2 (1.8 to 2.6$)$ & 216 & 4.1 (3.6 to 4.6$)$ & 10.0 (8.8 to 11.5$)$ \\
\hline $55-64$ & 13918 & 329 & $2.4(2.2$ to 2.7$)$ & 692 & 5.3 (4.9 to 5.7$)$ & $5.0(4.6$ to 5.4$)$ \\
\hline $65-74$ & 30661 & 1301 & $4.3(4.1$ to 4.5$)$ & 2822 & 9.7 (9.4 to 10.1$)$ & $3.3(3.2$ to 3.4$)$ \\
\hline $75-84$ & 36086 & 2752 & $7.8(7.5$ to 8.0$)$ & 6070 & $17.9(17.4$ to 18.3$)$ & $2.3(2.2$ to 2.3$)$ \\
\hline$\geq 85$ & 13822 & 2153 & $15.8(15.2$ to 16.4$)$ & 4315 & 32.8 (32.0 to 33.7$)$ & $1.7(1.6$ to 1.7$)$ \\
\hline Total & 100067 & 6654 & 6.7 (6.5 to 6.8$)$ & 14115 & $14.7(14.5$ to 14.9$)$ & $2.2(2.2$ to 2.3$)$ \\
\hline \multicolumn{7}{|c|}{ Precipitated acute urinary retention } \\
\hline $45-54$ & 4979 & 276 & $5.6(5.0$ to 6.3$)$ & 453 & $9.5(8.7$ to 10.4$)$ & 23.6 (21.5 to 25.9$)$ \\
\hline $55-64$ & 8736 & 625 & 7.2 (6.7 to 7.8$)$ & 1043 & 12.5 (11.8 to 13.2$)$ & 12.0 (11.3 to 12.8$)$ \\
\hline $65-74$ & 20461 & 2095 & 10.3 (9.9 to 10.8$)$ & 3492 & $17.8(17.3$ to 18.3$)$ & 6.1 (5.9 to 6.3$)$ \\
\hline $75-84$ & 28148 & 4551 & 16.4 (15.9 to 16.8$)$ & 7711 & 28.7 (28.1 to 29.2$)$ & 3.7 (3.6 to 3.8) \\
\hline$\geq 85$ & 13655 & 3792 & $28.0(27.3$ to 28.8$)$ & 5983 & $45.4(44.6$ to 46.3$)$ & $2.4(2.3$ to 2.4$)$ \\
\hline Total & 75979 & 11339 & 14.8 (14.6 to 15.1$)$ & 18682 & 25.3 (24.9 to 26.3$)$ & 3.5 (3.5 to 3.6$)$ \\
\hline
\end{tabular}


to a similar extent in the corresponding age groups from $9.5 \%$ to $45.4 \%$.

Although the highest one year mortality was observed in the oldest age groups, the age specific relative increase in mortality was highest in the youngest age groups (table 1). In men aged 45-54 years, compared with the general population there was a 10 -fold increase in mortality in those with spontaneous acute urinary retention and an almost 24 -fold increase in mortality in men with precipitated acute urinary retention. The corresponding increases in men aged 85 and over were 1.7-fold and 2.4-fold, respectively.

More than a third of men with acute urinary retention had at least one major comorbid condition as defined by the Charlson score (table 2). As expected, comorbidity was more prevalent in men with precipitated rather than acute urinary retention $(43.5 \% v$ $29.1 \%$ ). The presence of comorbidity greatly increased mortality. For example, in men with spontaneous acute urinary retention aged 75-84 years, the most prevalent age group, the presence of comorbidity more than doubled the one year mortality, from $12.5 \%$ to $28.8 \%$. In men with precipitated acute urinary retention in the corresponding age group, the presence of comorbidity had a similar effect, and one year mortality increased from $18.1 \%$ to $40.5 \%$.

One year mortality was high in men with comorbidity in the oldest age group $(44.3 \%$ in spontaneous and $54.7 \%$ in precipitated acute urinary retention). The age specific relative increase compared with the general population, however, was again highest in the youngest age group (standardised mortality ratio $36.5 v 60.4$, respectively).

Even in men without comorbidity as defined by the Charlson score, mortality within the first year after acute urinary retention was considerably higher than in the general population (table 2). For example, in men with spontaneous acute urinary retention without comorbidity, mortality was 4.4 times higher than in the general population in the youngest age group and 1.4 times higher in the oldest age group. Similarly, in men with precipitated acute urinary retention without comorbidity, mortality was 8.4 times higher in the youngest age group and 2.0 times higher in the oldest age-group.

\section{DISCUSSION}

Mortality after primary acute urinary retention in men admitted to hospital is high. Overall, we found that one in seven men with spontaneous acute urinary retention and one in four with precipitated acute urinary retention died in the first year. Mortality increased strongly with age and the presence of comorbidity. Consequently, about half of the men aged 85 and over with at least one comorbid condition died within the first year after acute urinary retention. Although mortality in men under 55 without comorbidity is not as high, it was still at least four times higher than that observed in men of similar age in the general population.

\section{Methodological limitations}

We included only men who were admitted to hospital and did not consider those who were treated within primary care or solely in a hospital emergency department. Those patients might have been in a better overall condition than the patients who were admitted. According to a 2004 survey, however, only 10\% of UK urologists would not admit men presenting with acute urinary retention. ${ }^{17}$ Also, a Dutch epidemiological study, the only population based study to date in which the incidence of acute urinary retention was estimated through direct access to a prospectively collected primary care database, reported an incidence of 2.2 per 1000 men per year. ${ }^{3}$ This is lower than the incidence of 3.1 per 1000 men per year that we reported previously based on hospital admissions in England. ${ }^{4}$ We therefore consider it unlikely that we missed a substantial number of men.

Table 2 | Age specific mortality within one year after spontaneous and precipitated primary acute urinary retention and standardised mortality ratios (SMR) with and without comorbidity

\begin{tabular}{|c|c|c|c|c|c|c|c|c|}
\hline \multirow{3}{*}{$\begin{array}{l}\text { Age } \\
\text { group }\end{array}$} & \multicolumn{4}{|c|}{ Men without comorbidity (Charlson score 0 ) } & \multicolumn{4}{|c|}{ Men with comorbidity (Charlson score $\geq 1$ ) } \\
\hline & \multirow{2}{*}{$\begin{array}{c}\text { Total } \\
\text { admissions }\end{array}$} & \multicolumn{3}{|c|}{1 year } & \multirow{2}{*}{$\begin{array}{c}\text { Total } \\
\text { admissions }\end{array}$} & \multicolumn{3}{|c|}{1 year } \\
\hline & & Deaths & Rate $(95 \% \mathrm{Cl})$ & $\operatorname{SMR}(95 \% \mathrm{Cl})$ & & Deaths & Rate \% $(95 \% \mathrm{Cl})$ & $\operatorname{SMR}(95 \% \mathrm{Cl})$ \\
\hline \multicolumn{9}{|c|}{ Spontaneous acute urinary retention } \\
\hline $45-54$ & 4590 & 77 & $1.8(1.4$ to 2.2$)$ & $4.4(3.4$ to 5.4$)$ & 990 & 139 & $14.7(12.6$ to 17.2$)$ & $36.5(30.7$ to 43.1$)$ \\
\hline $55-64$ & 10987 & 232 & $2.3(2.0$ to 2.6$)$ & 2.1 (1.9 to 2.4$)$ & 2931 & 460 & $16.7(15.4$ to 18.2$)$ & $15.8(14.4$ to 17.4$)$ \\
\hline $65-74$ & 21981 & 1099 & $5.3(5.0$ to 5.6$)$ & $1.8(1.7$ to 1.9$)$ & 8680 & 1723 & $21.0(20.1$ to 21.9$)$ & $7.1(6.8$ to 7.4$)$ \\
\hline $75-84$ & 24155 & 2843 & $12.5(12.1$ to 13.0$)$ & $1.6(1.5$ to 1.6$)$ & 11931 & 3227 & 28.8 (27.9 to 29.6$)$ & 3.7 (3.5 to 3.8) \\
\hline$\geq 85$ & 9268 & 2400 & 27.3 (26.4 to 28.2$)$ & 1.4 (1.3 to 1.4$)$ & 4554 & 1915 & 44.3 (42.8 to 45.8$)$ & $2.3(2.2$ to 2.4$)$ \\
\hline Total & 70981 & 6651 & 9.9 (9.7 to 10.2$)$ & $1.6(1.5$ to 1.6$)$ & 29086 & 7464 & 27.2 (26.7 to 27.7$)$ & 3.7 (3.6 to 3.8) \\
\hline \multicolumn{9}{|c|}{ Precipitated acute urinary retention } \\
\hline $45-54$ & 3522 & 114 & $3.4(2.9$ to 4.1$)$ & $8.4(6.9$ to 10.1$)$ & 1457 & 339 & 24.3 (22.1 to 26.6$)$ & $60.4(54.2$ to 67.2$)$ \\
\hline $55-64$ & 5496 & 235 & $4.5(4.0$ to 5.1$)$ & 4.3 (3.8 to 4.9) & 3240 & 808 & $26.0(24.5$ to 27.6$)$ & 25.1 (23.4 to 26.9$)$ \\
\hline $65-74$ & 11426 & 880 & $8.1(7.6$ to 8.6$)$ & 2.7 (2.6 to 2.9 ) & 9035 & 2612 & $30.0(29.1$ to 31.0$)$ & 10.3 (9.9 to 10.7$)$ \\
\hline $75-84$ & 14869 & 2571 & 18.1 (17.5 to 18.8$)$ & $2.3(2.2$ to 2.4$)$ & 13279 & 5140 & 40.5 (39.6 to 41.3$)$ & $5.2(5.1$ to 5.4$)$ \\
\hline$\geq 85$ & 7578 & 2778 & 38.0 (36.9 to 39.2$)$ & $2.0(1.9$ to 2.0$)$ & 6077 & 3205 & $54.7(53.4$ to 55.9$)$ & 2.8 (2.7 to 2.9 ) \\
\hline Total & 42891 & 6578 & 16.1 (15.7 to 16.4$)$ & 2.3 (2.2 to 2.3$)$ & 33088 & 12104 & 38.1 (37.6 to 38.6 ) & $5.0(4.9$ to 5.1$)$ \\
\hline
\end{tabular}


The Charlson score based on administrative data underestimates the prevalence of comorbid disease. ${ }^{1819}$ Undetected comorbidity may account for our observation that men without comorbidity according to the Charlson score still had a higher mortality than the general population. None the less, we found that the Charlson score identified at least one comorbid condition in more than a third of men with acute urinary retention and that mortality was most increased in this group. A more accurate instrument could have shown an even more marked impact of comorbidity.

The reported mortality after acute urinary retention was based on the linkage between the HES database of all admissions to NHS hospitals in England and the mortality database of the Office for National Statistics. Most $(96 \%)$ patients had a date of death that was based on robust linkage methods that relied on an exact match of at least two of the NHS number (a unique 10 digit code allocated to an individual to enable identification for NHS health care), date of birth, and postcode. For these patients, we found contradictory linkage results (that is, an admission date after a date of death) in only $0.3 \%$ of patients. In the $4 \%$ of patients remaining, we used a less robust linkage method (partial match of date of birth and exact agreement of sex and postcode) and found contradictory results in $54 \%$ of the patients. As explained before, we assumed that men with contradictory mortality results were alive until the end of the study period. Sensitivity analyses of alternative assumptions showed that the mortality for all men within one year after acute urinary retention always changed by less than 0.5 percentage point, and in turn the relative increases in mortality compared with the general population did not change appreciably.

\section{Comparison with other studies}

We specifically looked at longer term mortality after acute urinary retention. The only other study to date that provides some evidence on mortality after acute urinary retention was carried out in five healthcare regions in the UK in the mid-1990s in 3966 men who underwent prostatic surgery. ${ }^{20}$ That found that the 1242 men who underwent a prostatectomy after acute urinary retention had a higher mortality in the first 90 days $(3.0 \%)$ compared with the 2724 men who had surgery for symptoms alone $(0.7 \%)$. Other studies that have reported on outcomes after acute urinary retention tend to focus only on recurrence and the need for prostatic surgery. ${ }^{42}$

Acute urinary retention shares several characteristics with fractured neck of femur. Both are acute and serious age related events that almost always result in hospital admission but do not directly cause death. Two English studies have recently reported the one year mortality in men after fractured neck of femur to be just over $40 \%{ }^{2122}$ Mortality clearly increased with age from $20 \%$ in men aged $65-69$ to $50 \%$ in men aged $85-89 .{ }^{21}$ Comorbidity was found to be an important predictor of outcome, with mortality in the first year about 1.5 times higher in patients with at least one comorbid condition than in patients without comorbidity. ${ }^{22}$

The comparison with fractured neck of femur shows that acute urinary retention constitutes a health problem of a similar magnitude. The overall one year mortality was $20 \%$, which is lower than that observed after fractured neck of femur. The incidence of primary acute urinary retention, however, is 3.1 per 1000 men per year, which is higher than the incidence of fractured neck of femur, estimated to be about 2.4 per 1000 men per year based on the HES database.

\section{Explanations for the increased mortality}

Though acute urinary retention is generally considered a urological emergency, serious consequences are rare with appropriate treatment. Our finding of a high mortality in the first year seems to contradict this. An obvious explanation for the increased mortality is that occurrence exposes men to risks associated with admission to hospital, catheter related and other nosocomial infections, and invasive procedures that often need a general anaesthetic.

While these factors do play a role, the high mortality seems to be linked mainly to comorbidity for several reasons. Firstly, the presence of comorbidity according to the Charlson score substantially increased mortality within patients of similar age and with the same type of acute urinary retention. Secondly, mortality was also higher in patients with precipitated rather than spontaneous retention. Precipitated retention occurs after a triggering event that is unrelated to the prostate and therefore a further indication of comorbidity. Thirdly, there seems to be a "dose-response" relation as the lowest mortality was found in patients with spontaneous retention and no comorbidity according to the Charlson score and the highest mortality in patients with precipitated retention and comorbidity. Lastly, a detailed inspection of the diagnostic fields in patients with spontaneous acute urinary retention and no comorbidity apparent showed that $58 \%$ of these patients had at least one diagnosis not related to the prostate and not captured by the Charlson score.

Of the patients who had comorbidity according to the Charlson score, irrespective of the type of acute urinary retention, about 30\% had cardiovascular disease, 25\% diabetes, 25\% chronic pulmonary disease, and $15 \%$ a malignancy. The relatively high prevalence of cardiovascular disease and diabetes is consistent with the findings of recent aetiological studies linking hypertension and metabolic syndrome with the progression of benign prostatic hyperplasia. ${ }^{78}$

\section{Clinical implications}

The high mortality that we observed in men admitted to hospital with acute urinary retention shows that they are a vulnerable group of patients. These observations reinforce the importance to the clinician of adopting a multidisciplinary approach in the assessment and 


\section{WHAT IS ALREADY KNOWN ON THIS TOPIC}

The incidence of acute urinary retention strongly increases with age

Acute urinary retention seems to be associated with severe systemic disease

\section{WHAT THIS STUDY ADDS}

One in seven men admitted to hospital with spontaneous acute urinary retention and one in four with precipitated acute urinary retention die within a year

Mortality is considerably higher in older men and in those with comorbidity

Patients with acute urinary retention are a vulnerable group and may benefit from urgent multi-disciplinary care to identify and treat comorbid conditions

management of such patients. ${ }^{23}$ Men with acute urinary retention should undergo a comprehensive investigation for comorbid disease. The extent to which mortality after acute urinary retention can be reduced, however, will depend on the nature and severity of the comorbidities involved and the effectiveness of the available treatments. For example, some patients will have comorbidity that is already optimally treated and for whom little further can be done.

Our observation that about half of the deaths after acute urinary retention occur within the first 90 days suggests that assessment of comorbidity must occur promptly. Indeed, perhaps screening for other morbidities should start in men presenting with lower urinary tract symptoms attributable to benign prostatic hyperplasia before they experience acute urinary retention.

\section{Research implications}

The two most important unanswered questions relate to the way in which comorbidities can be identified and the extent to which their treatment will reduce mortality after acute urinary retention. In our view, research building on administrative databases, such as the hospital episode statistics, enriched through linkage with additional clinical data seems to be the obvious next step to answer both questions. Firstly, administrative databases can provide near complete follow-up in terms of further treatment as well as death. Clinical data, perhaps collected prospectively in a subgroup of patients and linked to the administrative data at the individual patient level, will allow a further exploration of the impact of comorbidity according to its nature and severity. The results of this will inform the development of treatment strategies. Secondly, these strategies can then be evaluated with research designs that build on combining administrative data with data derived from clinical trials.

We thank the Department of Health for providing the hospital episode statistics data used in this study and Jim Lewsey, statistician at London School of Hygiene and Tropical Medicine and the Royal College of Surgeons of England, for his help with the extraction of the dataset.

Contributors: JNA, PJC, ME, and JHvdM designed the study; JNA and NS conducted the statistical analyses; JNA and JHvdM drafted the paper; NS, PJC, and ME commented on and contributed to the final version. JHvdM is guarantor.
Funding: INA was supported by the Bob Young Research Fellowship, the Dunhill Medical Trust, and the Royal College of Surgeons of England research fellowship scheme. JvdM received a national public health career scientist award from the Department of Health and NHS research and development programme.

Competing interests: None declared.

Ethical approval: Not required.

Provenance and peer review: Not commissioned; externally peer reviewed.

1 Jacobsen SI, Jacobson DJ, Girman Cl, Roberts RO, Rhodes T, Guess HA, et al. Natural history of prostatism: risk factors for acute urinary retention. J Urol 1997;158:481-7.

2 Meigs JB, Barry MJ, Giovannucci E, Rimm E, Stamper M, Kawachi I. Incidence rates and risk factors for acute urinary retention: the health professionals follow-up study. J Urol 1999;162:376-82.

3 Verhamme KM, Dieleman JP, van Wijk MA, Bosch JL, Stricker BH, Sturkenboom MC. Low incidence of acute urinary retention in the general male population: the triumph project. Eur Urol 2005;47:494-8.

4 Cathcart P, van der Meulen J, Armitage J, Emberton M. Incidence of primary and recurrent acute urinary retention between 1998 and 2003 in England. J Urol 2006;176:200-4.

5 McNeill SA, Hargreave TB. Alfuzosin once daily facilitates return to voiding in patients in acute urinary retention. / Urol 2004;171:2316-20

6 McVary KT. BPH: epidemiology and comorbidities. Am J Manag Care 2006;12:S122-8.

7 Michel MC, Heemann U, Schumacher H, Mehlburger L, Goepel M. Association of hypertension with symptoms of benign prostatic hyperplasia. J Urol 2004;172:1390-3.

8 Ozden C, Ozdal OL, Urgancioglu G, Koyuncu H, Gokkaya S, Memis A. The correlation between metabolic syndrome and prostatic growth in patients with benign prostatic hyperplasia. Eur Urol 2007:51:199-203.

9 Office of Populations Censuses and Surveys. Classification of surgical operations and procedures. 4th rev. London: HMSO, 1987.

10 National Statistics. Home of Official UK Statistics. Office for National Statistics. www.statistics.gov.uk.

11 National Centre for Health Outcomes Development. Hospital episode statistics (HES)-construction of continuous inpatient (CIP) spells and assessment of data quality. www.nchod.nhs.uk.

12 Roehrborn CG, Bruskewitz R, Nickel GC, Glickman S, Cox C, Anderson R, et al. Urinary retention in patients with BPH treated with finasteride or placebo over 4 years. Characterization of patients and ultimate outcomes. The PLESS Study Group. Eur Urol 2000;37:528-36.

13 Charlson ME, Pompei P, Ales KL, MacKenzie CR. A new method of classifying prognostic comorbidity in longitudinal studies: development and validation. / Chronic Dis 1987:40:373-83.

14 Romano PS, Roos LL, Jollis JG. Adapting a clinical comorbidity index for use with ICD-9-CM administrative data: differing perspectives. I Clin Epidemiol 1993:46:1075-9.

15 Nuttall M, van der Meulen J, Emberton M. Charlson scores based on ICD-10 administrative data were valid in assessing comorbidity in patients undergoing urological cancer surgery. I Clin Epidemiol 2006;59:265-73.

16 Breslow NE, Day NE. Statistical methods in cancer research. Volume II. The design and analysis of cohort studies. IARC Sci Publ 1987;82:1-406.

17 Manikandan R, Srirangam SJ, O'Reilly PH, Collins GN. Management of acute urinary retention secondary to benign prostatic hyperplasia in the UK: a national survey. BJU Int 2004;93:84-8.

18 Romano PS, Roos LL, Jollis JG. Furthering evidence concerning the use of a clinical comorbidity index with ICD-9-CM administrative data. J Clin Epidemiol 1993;46:1085-90.

19 Schneeweiss S, Maclure M. Use of comorbidity scores for control of confounding in studies using administrative databases. Int J Epidemiol 2000;29:891-8.

20 Pickard R, Emberton M, Neal DE. The management of men with acute urinary retention. BJU Int 1998;81:712-20.

21 Roberts SE, Goldacre MJ. Time trends and demography of mortality after fractured neck of femur in an English population, 1968-98: database study. BMI 2003:327:771-5.

22 Roche JJW, Wenn RT, Sahota O, Moran CG. Effects of comorbidities and postoperative complications on mortality after hip fracture in elderly people: prospective observational cohort study. $B M$ J 2005;331:1374

23 Kirby RS, Kirby M. The urologist as an advocate of men's health: 10 suggested steps toward helping patients achieve better overall health. Urology 2005;66:52-6.

Accepted: 7 October 2007 